\title{
Путнева А.С., Мищенко М.Н., Караваева Т.М. \\ Оценка уровня противомикробных пептидов в ротовой жидкости у лиц с кариесом на фоне различного статуса витамина D
}

ФГБОУ ВО «Читинская государственная медиџинская академия» Министерства здравоохранения РФ (Россия, Чита)

doi: $10.18411 / s r-10-06-2021-06$

\section{Аннотация}

Изучено содержание антимикробных пептидов в ротовой жидкости у 100 человек в возрасте от 19 до 23 лет. Из них 40 человек были лица с кариесом и нормальным уровнем активной формы витамина $\mathrm{D}\left(25(\mathrm{OH}) \mathrm{D}_{3}>30\right.$ нг/мл) и 40 - с уровнем $25(\mathrm{OH}) \mathrm{D}_{3}<30$ нг/мл. Контрольную группу составили 20 человек с низким индексом КПУ $(1,5)$ и нормальным уровнем $25(\mathrm{OH}) \mathrm{D}_{3}$ в крови. Установлено, что содержание антимикробных пептидов - кателицидина LL-37 и $\alpha$-дефензинов 1-3 в слюне у лиц с кариесом на фоне нормального уровня $25(\mathrm{OH}) \mathrm{D}_{3}$ в организме увеличивается, а при недостатке - существенно снижается.

Ключевые слова: кариес, ротовая жидкость, противомикробные пептиды, витамин D.

Активный кариес зубов, являясь многофакторным заболеванием, широко распространенным как среди детей, так и лиц молодого возраста, представляет собой важную проблему общественного здравоохранения во всем мире. Считается, что в современном лечении кариеса от понятия «сверление и пломбирование» нужно переходить к оценке риска развития кариеса [5]. Имеющиеся многочисленные, но порой противоречивые данные о нарушениях некоторых показателей мукозального иммунитета полости рта при кариесе $[1,2]$ с одной стороны, и наличие информации о влиянии активной формы витамина $\mathrm{D}$ на эти показатели, а также выявленный дефицит витамина D y большей части населения, c другой стороны, определили целесообразность настоящего исследования.

Цель работы: установить особенности содержания антимикробных пептидов кателицидина LL-37 и $\alpha$-дефензинов 1-3 в слюне у лиц с кариесом на фоне различного статуса активной формы витамина $\mathrm{D}\left(25(\mathrm{OH}) \mathrm{D}_{3}\right)$ в организме.

Материалы и методы. В исследование были включены 100 человек в возрасте от 19 до 23 лет. Из них 40 человек с кариесом и нормальным уровнем активной формы витамина $\mathrm{D}\left(25(\mathrm{OH}) \mathrm{D}_{3}>30\right.$ нг/мл) в сыворотке крови были разделены на 2 группы в зависимости от интенсивности кариозного процесса: 1 группа - лица со средней (индекс КПУ 4-8), 2 группа - лица с высокой активностью (индекс КПУ- 9 и более).

Аналогичным образом были сформированы две группы по 20 человек в каждой с кариесом и уровнем активной формы витамина $\mathrm{D}$ в сыворотке крови ниже нормы $\left(25(\mathrm{OH}) \mathrm{D}_{3}<30\right.$ нг/мл): 3 группа - лица со средней интенсивностью кариозного процесса (индекс КПУ 4-8), 4 группа - лица с высокой активностью (индекс КПУ выше 9).

Контрольную группу составили 20 человек с индексом КПУ от 0 до 3 и нормальным уровнем $25(\mathrm{OH}) \mathrm{D}_{3}$ в крови.

Группы были сопоставимы по возрасту, полу, социальному статусу.

Исследование стоматологического статуса проводилось традиционными методами и инструментами.

Содержание метаболита витамина D - 25(OH)D3 в сыворотке крови проводилось методом хемилюминесцентного иммунного анализа (Access 2).

У всех лиц, принявших участие в исследовании, собирали ротовую жидкость, в которой определяли концентрацию антимикробного пептида - кателицидина LL-37, $\alpha$ - 
дефензинов 1-3 методом ИФА с использованием наборов реактивов «Нycult biotech», Нидерланды.

Анализ полученных проводили с помощью программы IBM SPSS Statistics для Macintosh версии 23.0 (IBM Corp., Армонк, Нью-Йорк, США).

Перед началом анализа вариационные ряды тестировались на нормальность, при помощи критерия Шапиро-Уилка. Для анализа данных использовали непараметрические методы статистики. Для количественных признаков множественные сравнения выполняли с применением критерия Краскела-Уоллиса, при выявлении различий проводили попарное сравнение групп с помощью критерия Манна-Уитни. Результаты представлены в виде медианы $(\mathrm{Me})$, первого и третьего квартилей. Статистически значимыми считали различия при $\mathrm{p}<0,05$.

Результаты и обсуждение собственных исследований.

Таблица 1

Содержание противомикробных пептидов в ротовой жидкости у лии в зависимости от интенсивности кариозного процесса и уровня 25(OH)D

\begin{tabular}{|c|c|c|c|}
\hline Показатели / Группы & $\begin{array}{c}25(\mathrm{OH}) \mathrm{D}_{3} \\
(\mathrm{H \Gamma} / \mathrm{M} \pi)\end{array}$ & $\begin{array}{c}\text { Кателицидин LL-37 } \\
\text { (нг/мл) }\end{array}$ & $\begin{array}{c}\alpha \text {-дефензины 1-3 } \\
\text { (нг/мл) }\end{array}$ \\
\hline $\begin{array}{l}\text { Контроль } \\
(\mathrm{n}=20)\end{array}$ & $\begin{array}{c}47,21 \\
(41,60 ; 50,15)\end{array}$ & $\begin{array}{c}36,17 \\
(18,45 ; 48,12)\end{array}$ & $\begin{array}{c}6884,2 \\
(583,9 ; 798,9)\end{array}$ \\
\hline 1 группа (n=20) & $\begin{array}{c}34,70 * \\
(32,20 ; 38,29) \\
\end{array}$ & $\begin{array}{c}49,34^{*} \\
(45,12 ; 57,11) \\
\end{array}$ & $\begin{array}{c}798,8 \\
(674,5 ; 899,4) \\
\end{array}$ \\
\hline 2 группа (n=20) & $\begin{array}{c}32,80 * \\
(31,19 ; 39,11)\end{array}$ & $\begin{array}{c}41,26 \\
(31,78 ; 55,99)\end{array}$ & $\begin{array}{c}807,2 * \\
(684,2 ; 1023)\end{array}$ \\
\hline 3 группа (n=20) & $\begin{array}{c}20,34 * \\
(18,48 ; 26,89) \\
\end{array}$ & $\begin{array}{c}21,00^{*} \\
(17,21 ; 23,12) \\
\end{array}$ & $\begin{array}{c}432,1 * \\
(379,0 ; 569,1) \\
\end{array}$ \\
\hline 4 группа (n=20) & $\begin{array}{c}19,35^{*} \\
(17,49 ; 25,40) \\
\end{array}$ & $\begin{array}{c}19,10^{*} \\
(14,88 ; 26,12)\end{array}$ & $\begin{array}{c}423,1^{*} \\
(378,9 ; 567,2) \\
\end{array}$ \\
\hline $\begin{array}{c}\text { Уровень достоверности } \\
\text { различий между всеми } \\
\text { группами }\end{array}$ & $\mathrm{p}<0,001$ & $\mathrm{p}<0,001$ & $\mathrm{p}<0,001$ \\
\hline
\end{tabular}

*-достоверные различия по сравнению с контролем

Анализ полученных данных показал, что у лиц с кариесом средней степени интенсивности при содержании $25(\mathrm{OH}) \mathrm{D}_{3}$ более 30 нг/мл была повышена концентрация кателицидина на $36,4 \%$ ( $<0,001)$ относительно контроля, однако в группе с кариесом высокой степени интенсивности при нормальном уровне витамина $\mathrm{D}$ значения данного пептида не отличались ни от контрольных, ни от таковых в первой группе. Тем не менее, в этой группе обследуемых выше контроля на 17,96\% (p=0,009) были концентрации дефензинов. В 3 и 4 группах (на фоне недостатка и дефицита витамина D) значения кателицидина были существенно снижены относительно контроля (на $41,94 \%(\mathrm{p}<0,001)$ и $47,19 \%(\mathrm{p}<0,001)$ соответственно и относительно групп с кариесом и нормальным уровнем $25(\mathrm{OH}) \mathrm{D}_{3}$. Тоже самое демонстрировали уровни дефензинов, которые были ниже контрольных на $36,84 \%(p<0,001)$ в 3 группе и на $38,16 \%(p<0,001)$ - в 4 группе.

Как кателицидины, так и дефензины проявляют широкую антибактериальную и противогрибковую активность, а также противовирусные свойства [1, 3, 4].

То есть на фоне нормальных значений витамина D в организме у пациентов с кариесом в ротовой жидкости повышается уровень противомикробных пептидов, возможно, как ответ на действие бактерий, вызывающих кариес. Падение же концентраций каталецидинов и дефензинов в группах с дефицитом витамина D, вероятно, свидетельствует о снижении активности мукозального иммунитета.

Вывод. Содержания антимикробных пептидов - кателицидина LL-37 и $\alpha$ дефензинов 1-3 в слюне у лиц с кариесом на фоне нормального уровня $25(\mathrm{OH}) \mathrm{D}_{3}$ в 
организме увеличивается, а при недостатке активной формы витамина D в организме существенно снижается.

$$
* * *
$$

1. Fábián T.K., Hermann P., Beck A., Fejérdy P., Fábián G. Salivary defense proteins: their network and role in innate and acquired oral immunity. // Int J Mol Sci. - 2012. - V. 13(4). P. 4295-4320.

2. Frenkel E.S, Ribbeck K. Salivary mucins protect surfaces from colonization by cariogenic bacteria. // Appl. Environ. Microbiol. - 2015. - V. 81. - P. 332-338.

3. Kahlenberg J.M., Kaplan M.J. Little peptide, big effects: the role of LL-37 in inflammation and autoimmune disease. // J. Immunol. - 2013. - V. 15. - P. - 191- 201.

4. Khurshid Z., Naseem M., Yahya I., Asiri F. et al. Significance and Diagnostic Role of Antimicrobial Cathelicidins (LL-37). Peptides in Oral Health. // Biomolecules. - 2017. - V. 7(4). - P. 80.

5. Pitts N.B. Detection, Assessment, Diagnosis and Monitoring of Caries. // Monogr Oral Sci. Basel, Karger. - 2009, V. 21.- 222 p.

\section{Чотчаев P.M.}

Анатомическое обоснование хирургических доступов к задней черепной ямке

Медицинская академия имени С. И. Георгиевского ФГАОУ ВО «КФУ им. В. И. Вернадского»

(Россия, Симферополь)

doi: $10.18411 /$ sr-10-06-2021-07

\section{Аннотация}

В данной статье имеется подробное описание, а так же техника выполнения доступов к задней черепной ямке, которые используются как в отечественной нейрохирургической практике, так и за рубежом. А именно описание ретросигмовидного, срединного субокципитального, парамедианного субокципитального и теменно - затылочного доступов, в положении лежа и сидя.

Ключевые слова: астерион, ЗЧЯ, диссекция, инион, инцизия, тракция, резекция.

В наше время, в области нейрохирургии прогрессивно практикуются оперативные методы лечения различных патологий задней черепной ямки (ЗЧЯ), таких как: злокачественные и доброкачественные новообразования основания черепа, мозжечка, различные посттравматические патологии.

Положения пациента на операционном столе при данных хирургических вмешательствах - полусидя и лежа. Наиболее предпочтения нейрохирурги отдают положению - лежа.

В полусидячем положении вентиляция легких обеспечивается лучше, а так же более лучшая визуализация оперативного поля, так-как жидкость стекает сама благодаря силе тяжести. Недостатком полусидячего положения является высокий риск возникновения воздушной эмболии, так же может наблюдаться изменение гемодинамики пациента, например - ортостатическая гипотензия.

Вышеуказанные осложнения не наблюдаются при лежачем положении пациента, по этому большинство нейрохирургов отдают предпочтения именно этому положению.

В наше время во всех крупных отечественных и зарубежных нейрохирургических центрах используют четыре основных вида доступов к задней черепной ямке: ретросигмовидный, парамедианно субокципитальный, срединный субокципитальный и теменно - затылочный доступы .

Ретросигмовидный доступ (РСД) - этот доступ практикуется нейрохирургами в течении многих лет.

Основными показаниями для выполнения данного доступа яввляются следующие патологии ЗЧЯ: 